\title{
A mídia como ator político: análise da Operação Monte Carlo a partir da cobertura do Jornal Nacional*
}

\section{The media like political actor: analysis of Operation Monte Carlo told by Jornal Nacional}

Isa Stacciarini ${ }^{1}$

* Recebido em: 04/05/2016. Aprovado em: 06/06/2016.

1 Jornalista. Doutoranda em Comunicação Social pela Universidade de Brasília (UnB). Mestra pela mesma instituição desde 2013. Professora de jornalismo do Centro Universitário de Brasília (UniCEUB). E-mail: isacoelho2@ gmail.com / isa.stacciarini@uniceub.br. Contato: +5561 3966-1426.

\section{Resumo}

O artigo investiga a hipótese do protagonismo da mídia como ator político no momento da narrativa da reportagem, quando o veículo de comunicação se posiciona dentro do enredo. Além disso, a pesquisa, também, recai na observação a partir do momento em que a mídia coloca, estrategicamente, os personagens da notícia uns contra os outros, chamados de conflito da narrativa. A análise se dá na Operação Monte Carlo narrada pelo Jornal Nacional no período de 29 de fevereiro de 2012, quando o chefe da quadrilha Carlos Augusto de Almeida Ramos, mais conhecido como Carlinhos Cachoeira foi preso, até a instalação da Comissão Parlamentar Mista de Inquérito (CPMI), ocorrida em 25 de abril de 2012, criada para investigar a relação do bicheiro com parlamentares e empresários.

Palavras-chave: Ator político. Narrativa. Conflito da narrativa. Operação Monte Carlo.

\begin{abstract}
The article investigates the guess of the media role as a political actor at the time of narrative of the story, when the communication media is within the plot. In addition, the research also observes the moment when the media strategically position the characters of news against each other's, called narrative conflict. The analysis takes place in Operação Monte Carlo told by Jornal Nacional in the period from February 29th of 2012, when the head of the gang Carlos Augusto de Almeida Ramos, known as Carlinhos Cachoeira is stuck, until the installation of the Comissão Parlamentar Mista de Inquérito (CPMI), which occurred on April 25th of 2012, set up to investigate the Cachoeira's relationship with Congressman and businessman.
\end{abstract}

Keywords: Political actor. Narrative. Narrative conflict. Operação Monte Carlo. 


\section{A mídia como ator político}

A partir de uma estória ou fato narrado pelo veículo de comunicação, a mídia se opõe, em alguns casos, como ator político. Dessa forma, o telejornal, o rádio e até mesmo o jornal impresso se enquadram no cenário em que a narrativa acontece. Assim, o veículo acaba por ocupar um protagonismo dentro do acontecimento político, se tornando personagem de sua própria publicação.

Motta (2002) explica que as sociedades passaram a ser impulsionadas por uma lógica midiática. Segundo ele, a mídia passou a ser a instituição política, ideologicamente, mais notável da sociedade, inclusive, suplantando outros poderes, como o Parlamento no jogo político.

O processo político ficou inexoravelmente dependente e condicionado e passou a ser um prolongamento da mídia em geral e da imprensa em particular. Há muito a imprensa (e o resto da mídia) deixou de apenas intermediar o real e o simbólico para estruturar e constituir o real. É a imprensa que seleciona, tipifica, descontextualiza e recontextualiza, estrutura e referencia o real. Nesse contexto, a política mistura-se com a performance, as eleições são disputas de marketing, políticos são mais atores que ideólogos, todos desempenhando papéis cujo fim é o espetáculo em si. A ação política é valorizada não pelo conteúdo das discussões, mas pelas habilidades teatrais e comunicativas dos atores, ou melhor, dos marqueteiros que "interpretam" a política. Nessa atmosfera mercadológica, a notícia é curta, rápida, fragmentada; tende ao entretenimento, esvaziada que é no seu conteúdo político (MOTTA, 2002, p. 17).

Além disso, há momentos em que a mídia assume a própria ação política e se coloca como o herói da estória, sendo aquele que denuncia, publicamente, acusa, cobra explicações, posicionamentos, ações, resultados e desmascara a falsidade da política. A maioria das ações como furo de reportagem, denúncias exclusivas, entrevista com fontes são atitudes, intencionalmente, propositais do veículo de comunicação para mostrar uma apuração de qualidade diante dos concorrentes e dos próprios receptores das informações. Dessa forma, a postura da mídia é uma das evidências do protagonismo do jornal como ator político.

O jornalismo é um conjunto de estórias que devem ser contadas pelos narradores, os jornalistas. Segundo ele, os profissionais são os "modernos contadores de 'estórias' da sociedade contemporânea, parte de uma tradição mais longa de contar 'estórias"' (TRAQUINA, 2005, p. 21).

Poder-se-ia dizer que o jornalismo é um conjunto de 'estórias', 'estórias' da vida, 'estórias' das estrelas, 'estórias' de triunfo e tragédia. Será apenas coincidência que os membros da comunidade jornalística se refiram às notícias, a sua principal preocupação, como 'estórias'? Os jornalistas vêem os acontecimentos como 'estórias' e as notícias são construídas como 'estórias', como narrativas, que não estão isoladas de 'estórias' e narrativas passadas. (TRAQUINA, 2005, p. 21)

Por outro lado, os conflitos da narrativa contribuem para que os personagens possam ser classificados como "heróis" ou "vilão" dos fatos, considerados neste artigo como aqueles que possuem um tratamento favorável, positivo, ou desfavorável, negativo, de acordo com a configuração dos fatos, propositalmente, publicados pelos veículos de comunicação. Em alguns casos, por uma opção do próprio jornal ou por decisão editorial, a estória é narrada para que o ouvinte, telespectador e/ou leitor, possa ter uma boa ou má impressão de um ou outro lado envolvido nos fatos.

Seria tarefa, dever e responsabilidade dos veículos de comunicação publicar reportagens de forma neutra, imparcial e sem deixar que as opiniões e posições pessoais dos jornalistas, editores e donos dos jornais possam interferir no processo de comunicação. Porém, nem sempre as reportagens jornalísticas apresentam notícias objetivas e parciais.

Essa "verdade jornalística" é muito mais do que simples precisão. É um processo seletivo que se desenvolve entre a matéria inicial e a interação entre o público leitor e os jornalistas, ao longo do tempo. Esse princípio básico do jornalismo - a busca desinteressada da verdade - é, em última instância, o que diferencia a profissão de todas as outras forma de comunicação. (KOVACH; ROSENSTIEL, 2003, p. 68)

Além disso, em relação à teoria estudada nos cursos de graduação em Comunicação Social, os futuros jornalistas aprendem que o papel do jornalismo é o de informar o público sem censura. Contudo, Traquina (2005) explica que existe uma relação simbiótica entre jornalismo e democracia na teoria democrática, mas ela define um papel adversarial entre o poder político e o jornalismo, chamado de "Quarto Poder".

No novo enquadramento da democracia, como o princípio de "poder controla poder" (Power cheks Power), a imprensa (os media) seria o "quarto" poder em relação aos outros três: o poder executivo, o legislativo e o judicial. O novo designado "Quarto Poder", a imprensa, o jornalismo, necessitava de uma legitimidade para tranqüilizar os receios, justificar o seu lugar crescente na sociedade, e dar cobertura a um negócio rentável (TRAQUINA, 2005, p. 46-47). 
Por sua vez, diante de como as estórias são construídas, há momentos em que a narrativa atinge situações em que o telejornal estudado fornece mais destaque sobre o noticiário. É quando a narrativa caminha de forma igualitária. Com base emdeterminados pronunciamentos, denúncia, investigação ou descoberta, a publicação dos fatos se torna densa e carregada de fatos que inverte o curso da narrativa. Esses momentos são chamados pela pesquisadora como Pontos de Virada (PV), em que a estória chega ao ápice dos acontecimentos de interesse público.

Uma das hipóteses de maior relevância deste artigo é o fato de que o Jornal Nacional (JN) atua como ator político. Com isso, o veículo estabelece conflitos da narrativa, ou seja, posiciona os personagens de forma que eles possam ser identificados como entrevistado que tem um destaque positivo ou negativo diante dos fatos propositalmente estruturados pelo telejornal.

\section{Apontamentos metodológicos}

Para estudar tal hipótese recorre-se a análise pragmática da narrativa com o recurso da técnica de hermenêutica. Conforme detalhado por Cook (1998), o estudo será feito com base na performance das vozes ali inscritas: veículo e jornalista, que são atores sociais e políticos.

De acordo com Motta ${ }^{2}$ (2012), a metodologia da narrativa jornalística é uma construção discursiva mediada por três etapas, sendo o primeiro, pelo meio de comunicação que a veicula. "O jornal, revista, emissora ou portal, cada qual com suas singularidades técnicas, seu ethos, seus interesses comerciais e ideológicos particulares". Segundo o docente, ela é mediada, em segundo lugar, por um corpo de profissionais corporativos, sendo jornalistas, diagramadores, fotógrafos, cinegrafistas, editores, ilustradores, webmasters, que hierarquizam a apresentação dos fatos, enquadram e posicionam os protagonistas na estória de acordo com seus valores pessoais e interesses profissionais.

Além desses interesses, o texto jornalístico está
permeado, em terceiro lugar, de falas diretas ou
indiretas das inúmeras personagens-testemu-
nhas, que também se digladiam para configurar
a estória de acordo com a ótica de seus próprios

2 Jornalista, doutor pela Universidade de Wisconsin (USA), professor da Universidade de Brasília (UnB) e coordenador do Núcleo de Estudos sobre Mídia e Política (UnB). pontos de vista sobre os incidentes que presenciaram, participaram ou ouviram. Veículos, profissionais e fontes estão assim em contínua 'negociação' política e simbólica. (MOTTA, 2012, p. 8).

Portanto, este artigo tem o objetivo de analisar o desempenho político do veículo Jornal Nacional aplicando elementos da análise narrativa ao realizar a observação das reportagens veiculadas durante o período conhecido como Operação Monte Carlo³. A pesquisadora pretende identificar a posição da mídia como ator político e os principais conflitos narrados pelo telejornal no caso da quadrilha de jogos ilegais chefiada pelo bicheiro Carlos Augusto de Almeida Ramos, mais conhecido como Carlinhos Cachoeira.

O início do período da análise compreende da prisão do chefe da quadrilha, em 29 de fevereiro de 2012, até a instalação da Comissão Parlamentar Mista de Inquérito (CPMI), em 25 de abril de 2012.

Os 57 dias de análise em questão foram marcados por 11 acontecimentos principais, chamados de momentos de tensão ou Pontos de Virada (PV). São eles: a prisão do bicheiro Cachoeira; o pronunciamento do ex-senador Demóstenes Torres (ex-DEM-GO) na tribuna do Senado Federal; o pedido de afastamento do senador da liderança do DEM do Senado; a determinação da quebra de sigilo bancário de Demóstenes Torres a pedido da PGR; abertura de processo contra o senador Demóstenes Torres por quebra de decoro parlamentar; acordo entre Câmara dos Deputados e Senado Federal para a criação da Comissão Parlamentar Mista de Inquérito (CPMI); envolvimento do ex-chefe de gabinete do governador do Distrito Federal na quadrilha; o momento em que Demóstenes disse que vai provar a inocência; confirmação de que o ex-governador do DF, Agnelo Queiroz, já se encontrou com Cachoeira; criação da CPMI no Congresso e, por fim, a instalação da CPMI.

No entanto, no início do escândalo, o JN não publicou em todas as edições reportagens sobre o caso Operação Monte Carlo. Após Demóstenes subir à tribuna do Senado para se pronunciar sobre as possíveis acusações, no dia 06/03/2012, o veículo deixou de noticiar por 20 dias qualquer notícia sobre o assunto. O retorno do caso

3 A operação foi montada pelo Departamento da Polícia Federal para desarticular a organização de Carlinhos Cachoeira que explorava máquinas caça-níqueis e jogos de azar em Goiás. 
só voltou na mídia no dia 26/03/2012, quando a corregedoria do Senado pediu à PGR informações sobre a relação do ex-senador Demóstenes Torres com Cachoeira. Assim, também, ocorreu entre diversos momentos de tensão identificados pela pesquisadora.

Diante disso, apesar do período de 57 dias desde a prisão de Cachoeira até a instalação da CPMI, o JN publicou 28 notícias até o dia 25/04/2012, o que representa, aproximadamente, $50 \%$ das matérias noticiadas pelo veículo. Todas as 28 notícias foram assistidas, contudo foram selecionadas aquelas 11 chamadas de Pontos de Virada para concentrar a análise da mídia como ator político.

O principal objetivo do artigo é mostrar como a mídia se posiciona como ator político nas histórias em que são narradas pelo veículo ou jornalista. Dessa forma, a intenção não é recontar o acontecimento da Operação Monte Carlo publicado pelo JN no período da análise, mas sim identificar os conflitos dos acontecimentos e compreender como as estórias são narradas e noticiadas, a fim de favorecer determinado lado em detrimento de outro.

\section{Identificando os conflitos e intrigas na narra- tiva do JN}

Durante os dias de escândalo da Operação Monte Carlo, o JN posicionou os envolvidos no caso como personagens participativos dos fatos, identificando-os como "vilões" e "heróis" no desenrolar dos fatos. Além disso, o telejornal se intitula como um veículo que apresentou um papel político do acontecimento com base em publicações exclusivas, furos de reportagens e denúncias que serão analisadas em um tópico deste artigo acadêmico.

\subsection{Protagonistas e coadjuvantes}

O então senador Demóstenes Torres foi o principal personagem que ganhou destaque negativo no decorrer da estória narrada pelo telejornal. Durante o decorrer das reportagens, o JN apresenta o ex-congressista como um político desonesto e antiético que aproveitou do cargo no Senado Federal para beneficiar a quadrilha de jogos ilegais em troca de propina e presentes. Apesar de o telejornal veicular uma série de denúncias e acusações contra o ex-senador, na narrativa do dia 12/04/2012 a jornalista Patrícia Poeta anuncia pausadamente, antes de a matéria ir ao ar, que "Demóstenes Torres disse que vai provar a inocência”. A forma como a âncora do telejornal infor- mou os telespectadores o fato, de forma pausada e com expressões faciais, demonstra a ênfase que o JN quis dar à declaração de Demóstenes.

Ao lado do ex-senador, o telejornal noticia a imagem de Cachoeira como o empresário que mantinha casa de jogos ilegais e máquinas caça-níqueis. O JN apresenta o bicheiro como um corruptor comparsa de Demóstenes Torres. O empresário contava com a ajuda de uma série de auxiliares, como Idalberto Matias de Araújo, o Dadá, que mantinha contatos com demais empresários, como o diretor da empresa Delta e até mesmo com ex-assessores de políticos, como o do ex-governador do Distrito Federal Agnelo Queiroz, para beneficiar os trabalhos da quadrilha. Além disso, o contador da organização de Cachoeira, Giovani Pereira da Silva, fazia toda a contabilidade do dinheiro da operação chefiada pelo bicheiro.

Como coadjuvante estão a imagem dos advogados de Demóstenes Torres e Cachoeira. Os profissionais que agem com o intuito de amenizar a imagem negativa dos acusados trabalham de maneira que poderiam aliviar as acusações.

\subsection{Antagonistas e coadjuvantes}

Quanto aos antagonistas, logo nas primeiras reportagens, é possível perceber que a Polícia Federal e o Ministério Público são os principais protagonistas que se opõem ao ex-senador Demóstenes Torres e Cachoeira. O trabalho de investigação, espionagem, apuração e ligações grampeadas reforçaram, no decorrer das reportagens, a ligação entre o parlamentar e o empresário nas negociações para favorecer a quadrilha de jogos ilegais.

Além das organizações oficiais, também são colocados como antagonistas um grupo de senadores que, no dia 26/03/2012, ocupou a tribuna da Casa para pedir explicações de Demóstenes sobre a relação dele com o chefe da quadrilha. O JN noticiou que parlamentares também quiseram ter acesso ao relatório da Polícia Federal com escutas telefônicas que mostram a relação dos dois. Já no dia 27/03/2012, o mesmo grupo de políticos foi à Procuradoria-Geral da República (PGR) cobrar providências em relação às denúncias contra o ex-senador Demóstenes.

\subsection{Pontos de virada}

A) 29 de fevereiro: prisão do bicheiro Cachoeira No dia da prisão do bicheiro Cachoeira, a reportagem do JN enfatiza com destaque que "a quadrilha 
explorava o jogo do bicho e máquinas caça níqueis havia 19 anos" (grifo nosso). A matéria ainda veicula com ênfase que "segundo informações da Polícia Federal (PF) o esquema tinha participação de policiais e servidores públicos".

No desenrolar do enredo, o JN publica outra informação enfática ao dizer que mais de 30 pessoas foram presas, entre elas policiais. O valor de $\mathrm{R} \$ 180$ mil apreendido na casa de Cachoeira também é noticiado com realce, o identificando como suposto chefe da quadrilha e já divulgando o seu desfavor contra o bicheiro.

Além disso, o veículo ainda relembra que $\mathrm{Ca}$ choeira esteve envolvido no primeiro escândalo do governo de Luiz Inácio Lula da Silva. O JN traz as imagens do ano de 2002 referentes ao escândalo do Mensalão. O jornal noticia que o bicheiro ficou conhecido em 2004 após a divulgação de um vídeo em que Valdomiro Diniz, ex-assessor do então Ministro da Casa Civil José Dirceu, aparece supostamente, pedindo propina à Cachoeira.

6 de mar: pronunciamento do senador Demóstenes Torres na tribuna do Senado

O JN narra que "com autorização da Justiça a Polícia Federal gravou conversas telefônicas de cachoeira com políticos goianos, ente eles Demóstenes". O telejornal ainda dá ênfase ao informar que "a polícia teria o registro de quase 300 conversas entre os dois".

Logo depois, o veículo mostra o seu desfavor ao ex-senador, dizendo que "no entanto, mesmo com as ligações grampeadas, o senador subiu à tribuna e afirmou que ele e a esposa são amigos de Cachoeira e de sua mulher e inclusive receberam presentes luxuosos, como fogão e geladeira".

Além disso, a reportagem do JN sempre relembra as pessoas acusadas de participar da quadrilha do jogo do bicho e, também, faz referência ao primeiro escândalo do governo Lula em que Cachoeira esteve envolvido.

B) 27 de março: o pedido de afastamento do senador da liderança do DEM

$\mathrm{O} J \mathrm{~N}$ inicia a matéria mostrando a nota que o ex-senador Demóstenes Torres comunicou ao presidente do partido DEM o seu afastamento da liderança do partido para acompanhar a evolução dos fatos noticiados nos últimos dias. $\mathrm{O}$ veículo relembra que ele é suspeito de manter relações com Cachoeira. Posteriormente, o telejornal explica que o partido escolheu novo líder, senador Agripino Maia, que acumulou o cargo com a presidência do Democratas.
O telejornal mostra outra nota enviada ao presidente do Senado, dessa vez com tom de ênfase, em que Demóstenes afirmou: "que está sofrendo nas últimas semanas ataques à sua honra sem que sejam observadas as garantias constitucionais previstas em qualquer Estado Democrático de direito e que vai ocupar a tribuna do Senado tão logo tenha acesso ao conteúdo dos autos que estão em poder da Procuradoria-Geral da República (PGR)".

Posteriormente, o JN mostra o grupo de parlamentares que foi à procuradoria cobrar providências em relação às denúncias. Relembra que desde 2009 o Ministério Público Federal (MPF) tem informações sobre o envolvimento de Cachoeira com deputados e senadores. C) 29 de março: a determinação da quebra de sigilo bancário de Demóstenes Torres

O JN inicia a matéria noticiando que o STF determinou a quebra do sigilo bancário do ex-senador e abriu inquérito para investigar a relação dele com Cachoeira. $\mathrm{O}$ veículo se apresenta como ator político na narrativa, dizendo que "O JN teve acesso a novos trechos de gravações de conversas de Cachoeira".

Posteriormente, o telejornal veicula que naquele dia Demóstenes não foi ao congresso. Segundo a narrativa, "advogados e amigos tem sugerido que ele renuncie e no Senado colegas pedem pressa no caso".

Logo depois, o veículo se mostra, novamente, dentro do enredo, publicando que

"ontem o JN mostrou com exclusividade gravações feitas pela PF da Operação Monte Carlo que prendeu Cachoeira. Nos diálogos, Cachoeira conversa com contador e suposto sócio e fala da contabilidade da negociação. Eles discutem o destino de milhões de reais e o nome Demóstenes é citado seis vezes".

Por fim, o JN veicula com destaque que o então ministro do STF, Ricardo Lewandowski, autorizou abertura de inquérito para investigação, além de determinar a quebra de sigilo da conta de Demóstenes por dois anos. "O STF determinou que a PF faça a transcrição de 19 conversas que integram o inquérito e autorizou que senador tenha acesso aos documentos da investigação".

D) 10 de abr: quebra de decoro/criação CPMI ganha força. Envolvimento do chefe de gabinete do ex-governador do DF Agnelo Queiroz

Quebra de decoro/criação CPMI ganha força

JN noticia que "se o Conselho de Ética decidir que Demóstenes deve ser cassado o pedido vai para plenário que será aceito ou não em sessão aberta com voto 
secreto. $\mathrm{O}$ relator do processo será sorteado entre os integrantes dos conselhos".

Posteriormente, o telejornal publica que a criação de uma CPMI ganhou força reunindo 11 senadores e 11 deputados federais. Por fim, o JN veiculou com ênfase que a defesa de Demóstenes recorreu ao STF para arquivar a investigação contra ele. "O advogado alega que as conversas só poderiam ser gravadas com autorização do STF”.

Envolvimento do chefe de gabinete do governador do DF Agnelo Queiroz

O veículo inicia a narrativa com a intenção de denúncia. O telejornal veicula que as gravações da PF na Operação Monte Carlo envolveram no escândalo o ex-chefe de gabinete do então governador Agnelo Queiroz do PT, Cláudio Monteiro. "Na ligação entre o diretor da Delta, Cláudio Abreu e Dadá, discutem o pagamento de mesada para ter benefícios no contrato do setor de limpeza urbana (SLU)".

O veículo continua narrando que a conversa foi gravada em janeiro de 2011 e mostra os dois conversando da nomeação de aliado da quadrilha na direção do SLU, área de interesse da Delta."Os dois integrantes da quadrilha citam dois nomes: Marcelo Lopes, ex-assessor da Casa Militar do GDF, e Cláudio Monteiro, chefe de gabinete do governador".

Logo após o JN oferece um pequeno espaço em que o chefe de gabinete do governador Cláudio Monteiro admite que recebeu, em audiência, Dadá e Cláudio Abreu, mas nunca favoreceu empresa nem recebeu dinheiro: "Não providenciei nomeação e nem recebi dinheiro, não tem nada a ver com isso".

O JN continua, com ênfase, veiculando que "em outra ligação assessores do governador Agnelo foram novamente situados em conversa de Dadá e Cachoeira que falam sobre entrega de rádio para facilitar comunicação com Marcelo Lopes e Cláudio Monteiro”.

Por fim o JN notifica que o ex-diretor do SLU, João Monteiro, se defendeu ao dizer que nunca teve contato com a quadrilha nem facilitava negócios para empresa Delta. "A Delta declarou que não tem qualquer relação impropria com João Monteiro e disse que afastou Cláudio Abreu devido relações com Cachoeira. Já Marcelo Lopes não comentou sobre as denúncias e o advogado de Dadá disse que só vai se pronunciar quando tiver acesso ao inquérito".
Confirmação de que Agnelo tenha encontrado Cachoeira:

Demóstenes diz que vai provar inocência

JN anuncia na escalada que Demóstenes disse que vai provar inocência. Ao narrar o fato, Patrícia Poeta informa o acontecimento de maneira pausada e com expressões faciais, em que fica perceptível a intenção do veículo em desacreditar do ocorrido.

Logo após, a passagem do jornalista informa que o ex-senador apareceu logo antes do início da sessão de Comissão de Ética. Posteriormente, o veículo divulga uma sonora do entrevistado que diz: "quero provar minha inocência no mérito. Até agora não tive oportunidade de me defender e o foro competente a isso. E eu farei. Farei e provarei que sou inocente".

Confirmação de que Agnelo tenha encontrado Cachoeira:

O JN publica entrevista que mostra o ex-governador Agnelo Queiroz negando qualquer envolvimento com a quadrilha de Cachoeira. $\mathrm{Na}$ ocasião, ele afirma que não tinha se encontrado com o bicheiro. De forma a contradizer o entrevistado, o telejornal veicula entrevista do então porta-voz do governo, Ugo Braga, dizendo que Agnelo negou, pois se referia ao encontro com Cachoeira depois que a quadrilha foi grampeada. O JN narra que Braga admite que, em ocasião anterior, o ex-governador e Cachoeira se encontraram. O veículo publica uma sonora do entrevistado. "O governador foi apresentado à cachoeira em 2009 ou 2010 em visita farmacêutica à Anápolis onde estavam vários empresários do ramo inclusive Cachoeira. Ele foi apresentado à Cachoeira e teve contato nesta única ocasião, no mais, nenhuma”.

Logo após o JN faz referência aos jornais Folha de S. Paulo e Estado de São Paulo que publicaram reportagem sobre ligações grampeadas. Posteriormente, o telejornal publica que outra gravação "foi mostrada em primeira mão no jornal da Globo", o que, mais uma vez, reforça a mídia como ator político.

F) 19 de abril: criação da CPMI

Na cabeça do telejornal, Patrícia Poeta narra com ênfase que o "Congresso Nacional criou hoje oficialmente a CPMI que vai investigar as relações da quadrilha do bicheiro com políticos e empresários. A comissão vai começar a funcionar na semana que vem”.

Durante o decorrer da reportagem, o JN explica as investigações da CPMI. Além disso, o telejornal adota uma postura denunciativa ao narrar que "a proximidade 
entre elas está cada vez mais clara como mostram gravações feitas com autorização da Justiça. Em uma delas, o bicheiro aparece conversando com um empresário e se comporta como se fosse representante da Delta".

$\mathrm{O}$ veículo ainda cita levantamentos dos jornais Folha de S. Paulo e Estado de S. Paulo que mostraram repasse de dinheiro realizado pela empresa Delta. Logo depois o JN informa com destaque que Cachoeira "foi transferido da Prisão de Segurança Máxima em Mossoró para a penitenciária da Papuda e os senadores temem que ele possa ser assassinado".

G) 25 de abril: instalação da CPMI

Logo na cabeça, Patrícia Poeta anuncia, de forma enfática, que a "CPI vai investigar os negócios de Cachoeira com políticos e empresários”. Logo depois a reportagem anuncia que "hoje parlamentares já requisitaram as informações obtidas em operações policiais".

O JN narra que, após a confirmação dos nomes do presidente e relator, a CPI aprovou por unanimidade seu primeiro requerimento: pediu ao Supremo Tribunal Federal (STF), Procuradoria-Geral da República (PGR) e a Polícia Federal (PF) copia dos inquéritos da operação Vegas e Monte Carlos.

Logo depois, o telejornal noticia que "mesmo em minoria o PSDB e DEM apresentaram 73 requerimentos pedindo que seja ouvidas 16 pessoas, dentre elas Marconi Perillo, governador de Goiás do PSDB e Agnelo Queiroz, governador Distrito Federal do PT".

Continuando a narrativa, a oposição sugeriu a criação de subrrelatorias: o então senador, presidente da CPI Vital do Rêgo (PMDB-PB), se manifestou a favor da criação, dizendo que isso "vai seguramente levar, em nossa opinião, a uma melhoria e organização de trabalho a subdivisão de setores. Esperamos que possamos participar e ajudar em uma das subrelatorias”. E o JN mostra a versão dos aliados. "Mas os aliados do governo querem manter o poder do relator, que é do PT".

\section{Considerações finais}

Durante o período em que o JN noticiou com destaque os fatos da Operação Monte Carlo ficou perceptível a intenção da mídia televisiva em mostrar personagens que tiveram destaque de "vilões", chamados de menos favorecidos e que apresentaram um aspecto desfavorável sobre os acontecimentos. Por outro lado, o veículo mostrou outros personagens que tomaram uma posição de "heróis" sobre os fatos, considerado como aqueles que apresentaram uma figura favorável e positiva em relação à narrativa.

Assim, devido à posição do próprio telejornal em colocar os lados da estória em posições de conflito, identifica-se uma forma proposital do JN em colocar os envolvidos como protagonistas e antagonistas diante do mesmo fato narrado. A maneira como essas posições ocorrem no ato da veiculação da notícia acaba por seduzir o receptor da informação, telespectador, em formar uma opinião contra ou a favor de determinado grupo com base no que foi influenciado pela mídia emissora da narração.

No entanto, na cobertura dos fatos relacionados ao jornalismo político, é possível encontrar veículos das mais variadas formas de transmissão da informação, como rádio, impresso e até mesmo blogs de jornalistas que narram a estória em prol de alguns dos lados. Com base em uma posição meramente partidária, a mídia, em alguns casos, realiza a cobertura dos fatos em favor da definição política do veículo de comunicação. Já no caso dos blogs, devido à autonomia do próprio jornalista que é o responsável pelo veículo, a narrativa é feita em prol da própria posição de partido do repórter e/ou parlamentar.

Nos 11 Pontos de Virada observados durante o estudo do telejornal, foi possível identificar, em todos os momentos, a posição política ou a intenção de conflito durante a narrativa dos fatos ocorrida pelo JN. Em relação ao total de narrativas, em cinco houve a presença tanto do veículo, que se fez participar do conto, quanto a postura do JN em estrategicamente posicionar os envolvidos uns contra os outros. Os dias em que os dois fatos se tornam presente nas narrativas foram em 6, 27, 29 de março, um dos acontecimentos do dia 12 de abril, quando o ex-senador Demóstenes prova inocência, além da reportagem do dia 19 de abril. Sendo assim, pode-se dizer que, em $45 \%$ das reportagens publicadas pelo JN, há a intenção política e conflituosa por parte do veículo.

Já dos 11 Pontos de Viradas, quatro representam, apenas, os conflitos políticos, quando o telejornal dispõe um grupo dos personagens do fato contra outro, sendo os dois acontecimentos do dia 10 de abril, o segundo ocorrido no dia 12 de abril, quando o ex-governador do DF, Agnelo Queiroz, confirma que se encontrou com Carlinhos Cachoeira e a reportagem do dia 25 de abril. Diante disso, pode-se afirmar que em 36\% das reportagens fica explícita a posição estratégica de conflitos da narrativa pelo 
JN. Por sua vez, apenas o dia 29 de fevereiro contempla somente a postura do veículo como ator político.

\section{Referências}

COOK, Timothy E. Governing with the news: the news media as a political institution. Chicago: University of Chicago Press, 1998.

KOVACH, Bill; ROSENSTIEL, Tom. Os elementos do jornalismo: o que os jornalistas devem saber e o público exigir. São Paulo: Geração, 2003.
MOTTA, Luiz Gonzaga. Análise crítica da narrativa. Brasília: EdUnB, 2013.

MOTTA, Luiz Gonzaga. Imprensa e poder. Brasília: EdUnB; São Paulo: Imesp, 2002.

TRAQUINA, Nelson. Teorias do jornalismo: porque as notícias são como são. Florianópolis: Insular, 2005. v. 1. 